\title{
PERBANDINGAN UNSUR-UNSUR DEUS EX MACHINA DALAM PAK BELALANG DAN RUMPELSTILTSKIN
}

\author{
Essy Syam \\ Universitas Lancang Kuning, Pekanbaru \\ essy_fib@yahoo.com
}

\begin{abstract}
This writing compares the elements of deux ex machina in two folklores entitle "Pak Belalang" and "Rumpelstiltskin". Thus, the objective of the research is describe and analyze the similarities and differences of the elements of deux ex machina used in eastern and western folklores because these two chosen folklores reflect the tendency of both easterners and westerners in using the elements of deux ex machina in creating the folklores. Related to that, this analysis applies descriptive analysis in which the result of the analysis will be described clearly. From the description, it will show the tendency of the eastern and western's texts in making good use of the elements of deux ex machina which may determine the aesthethic elements of a literary work.
\end{abstract}

Keywords: Pak Belalang, Rumpelstiltskin, deux ex machina, Comparative literature.

\section{Pendahuluan}

Dalam sebuah karya sastra dapat ditemukan berbagai unsur yang membangun sebuah karya sehingga dengan adanya unsurunsur tersebut sebuah karya menjadi kaya dengan hal-hal yang dapat diamati dan dianalisis. Unsur-unsur yang membangun sebuah karya sangat banyak. Salah satu unsur yang menarik adalah konflik. Konflik yang tercipta dalam sebuah karya dapat memberikan rasa penasaran dan keingintahuan pembaca terhadap kejadian yang menimpa tokohnya karena itulah konflik dalam sebuah karya dapat menjadi bagian yang sangat berpengaruh terhadap pembaca.

Salah satu konflik yang menarik adalah kondisi yang 
menempatkan tokoh dalam karya

pada suatu situasi yang sulit atau

suatu keadaan yang seperti tidak memiliki jalan keluar. Si tokoh ibarat dikepung dengan mata pisau yang siap dilempar dan mengenai tubuhnya dari berbagai sisi. Pada situasi seperti ini tentu akan menimbulkan ketegangan dan rasa ingin tahu pembaca terhadap nasib tokoh tersebut. Kondisi dan situasi seolah tanpa solusi ini dapat ditemukan dalam beberapa karya. Namun rupanya ada kejadian mengejutkan dengan hadirnya "pertolongan" yang memberi kemudahan terhadap sang tokoh sehingga semua permasalahan dapat terselesaikan dengan mudah.

Dalam beberapa keadaan, hadirnya "pertolongan" ini membuat konflik menjadi tidak lagi terasa "menggigit" karena pertolongan tersebut membuat semua menjadi mudah. Dalam keadaan tertentu "pertolongan" ini hadir dengan tiba-tiba dan terkesan begitu dipaksakan untuk menyelamatkan sang tokoh. Dalam karya tertentu "pertolongan" ini (yang dinamakan deux ex machina) bahkan hadir secara superstitious sehingga terkesan tidak masuk akal.

Terlepas dari ada tidaknya atau besar kecilnya pengaruh yang ditimbulkan oleh deux ex machina ini terhadap kualitas suatu karya, sebagian karya masih mengandalkan unsur ini dalam membangun konflik apalagi karya-karya folklore yang masih berbau superstitious.

Terkait dengan hal itu, kajian ini akan membandingkan unsur-unsur deux ex machina dalam dua folklor berjudul Pak Belalang dan Rumpelstiltskin, dimana dua folklor ini dapat memperlihatkan bagaimana teksteks Timur dan Barat menggunakan unsur-unsur deux ex machina dalam mambangun konflik pada teks cerita.

\section{Konsep}




\section{a. Deux Ex Machina}

Deux ex machina berasal dari bahasa Yunani kuno yang berarti "god from the machine". Dalam sebuah karya drama istilah ini merujuk pada kondisi yang mempercayai bahwa Tuhan berada di panggung untuk memutuskan atau memecahkan masalah yang dihadapi sang tokoh atau untuk menentukan takdir tokoh tersebut.

Saat ini deus ex machina dimaknai dengan konotasi yang negatif karena dianggap menampilkan alur yang tidak mungkin, tidak logis, dan tidak berdasar yang secara drastis mengubah situasi seolah-olah deux ex machina ini datang tibatiba menciptakan takdir yang agak memaksa.

Beberapa tanggapan yang
muncul
kemperlihatkan
karya yang menggunakan unsur
deux ex machina ini seperti
seseorang yang mengatakan

bahwa ia menyukai karya tersebut namun karya itu diakhiri dengan ending yang benar-benar buruk, padahal karya tersebut dapat saja diakhiri dengan lebih baik.

Secara literal, deux ex machina berarti "Tuhan dari mesin" dimana Tuhan dipercayai muncul untuk memberikan solusi terhadap permasalahan yang ada di dalam karya tersebut, “.... where the "gods" would be lowered onto he stage in order to provide a quick resolution to the story. “ Dalam hal ini Deus Ex Machina dimaksudkan sebagai segala kemungkinan, seorang tokoh, atau mekanisme yang datang dari tempat yang tidak diketahui secara tiba-tiba menyelamatkan tokoh dari penderitaan atau kesulitan.

Selanjutnya, deux ex machina juga dimaknai sebagai suatu cara melarikan diri atau melepaskan diri dari suatu keadaan dengan dibantu oleh sesuatu atau seseorang yang tidak 


\begin{abstract}
terduga. Bagi sebagian pembaca unsur ini merupakan alat yang digunakan penulis dalam membangun alur cerita yang melemahkan karya itu dengan tujuan menyelamatkan tokohnya.
\end{abstract}

Dalam sebagian besar
karya, deux ex machina hadir
pada akhir cerita
melibatkan sesuatu yang
terduga yang
mengabaikan logika dari
pembaca, "A story ending that
involves something inexplicable
and unexpected, which usually
requires a suspension of logic
from the audience."

\section{A deus ex machina yang} secara literal diartikan sebagai "god from machine." Memiliki beberapa ciri-ciri sebagai berikut:

1. Sebagai kekuasaan atau kekuatan yang tidak terduga (an unexpected power) atau kejadian yang muncul dengan kekuatan yang tidak terduga dalam situasi yang genting dimana tokoh berada pada situasi yang putus harapan khususnya sebagai alat pembangun alur dalam sebuah karya baik itu prosa atau drama.Keadaan ini memperlihatkan peran "the invisible hand."

2. Suatu cara yang tidak logis, tidak terduga dan tidak pada tempatnya untuk menyelamatkan sang tokoh.

Karena itulah device ini menyajikan situasi yang tidak menyenangkan bagi sebagian besar pembaca atau penonton karena situasi yang diciptakan adalah kondisi yang sangat tidak memungkinkan namun tiba-tiba datanglah sesuatu atau seseorang dari tempat yang tidak diketahui menawarkan solusi terhadap masalah yang serba rumit itu.

\section{Dengan situasi seperti ini} keadaan yang terjadi menjadi tidak logis dan kejadian itu 
disisipkan sepagai upaya untuk mengakhiri cerita. Jadi deus ex machina terasa sangat dipaksakan sehingga kehadiran unsur ini dalam berbagai situasi jadi mengurangi kualitas sebuah karya (http://www.urbandictionary.com/ define.php?term=Deus+Ex+Mach ina).

\section{b. Sastra Banding}

Sastra Banding merupakan studi tentang teks secara lintas budaya. Sastra banding merupakan suatu kajian interdisipliner yang melampaui batas area dengan mengungkapkan persamaan dan perbedaan antar teks atau antar pengarang dari teks budaya yang berbeda (Mahayana, 2009). Hal ini dimungkinkan karena, "Dimana-mana ditemukan hubungan dan ilustrasi. Tidak ada event yang tunggal atau kesusastraan yang dapat dipahami secara utuh kecuali dalam relasinya dengan event yang lain atau kesusastraan yang lain."
(Arnold, 1857). Lebih jauh lagi Benedetto Croce dalam Bassnett (1993) mengungkapkan, "Comparative literature is the exploration of 'the vicissitudes, alterations, developments, and reciprocal differences' of themes and literary ideas across literatures."

Sastra banding adalah kajian yang berupa eksplorasi perubahan (vicissitudes), penggantian (alteration), pengembangan (development), dan perbedaan timbal balik (tema) dua karya sastra atau lebih. Sastra banding adalah kajian teks-teks yang terfokus pada pola-pola hubungan dalam satra-sastra yang berbeda baik yang bersifat lintas ruang maupun lintas waktu.

$$
\begin{aligned}
& \text { Kajian sastra banding } \\
& \text { tidak harus } \\
& \text { membandingkan satu teks sastra } \\
& \text { dengan teks sastra yang lain. } \\
& \text { Bahkan kajian yang dilakukan } \\
& \text { lebih banyak membandingkan }
\end{aligned}
$$


teks-teks sastra dengan teks-teks non-sastra (Budiman, 2005).

Sastra banding mengkaji sastra di luar batas sebuah negara dan kajian tentang hubungan sastra dengan bidang ilmu atau kepercayaan lain seperti seni, filsafat, sejarah, ilmu sosial (politik, ekonomi, masyarakat) sains, agama, dll. Sastra banding merupakan sebuah kajian terhadap kesusastraan dua atau lebih dari karya yang berbeda bahasa, budaya dan negara. Dalam prakteknya, banyak pula dilakukan karya dari bahasa yang sama, bila karya tersebut berasal dari negara atau budaya yang berbeda. Lebih jauh lagi, dalam kajian yang banyak dilakukan, dapat pula dilakukan perbandingan antar karya seni yang berbeda. Contohnya, seorang komparatis dapat mengkaji hubungan sebuah film dengan kesusastraan.

\section{Pembahasan}

Hasil penelitian ini memperlihatkan adanya unsurunsur deux ex machina yang digunakan dalam dua cerita rakyat berjudul Pak Belalang dan Rumpelrstiltskin. Dalam teks Rumperlstiltskin lebih banyak ditemukan unsur deux ex machina dibandingkan dalam Pak Belalang. Teks Rumperlstiltskin menampilkan kejadian dimana masalah yang dihadapi putri pemilik pabrik secara tiba-tiba dan tidak terduga dengan mudah terselesaikan dengan kedatangan laki-laki kerdil yang menolongnya melakukan pekerjaan yang mustahil untuk dilakukn secara normal dan wajar. Namun, dengan kekuatan magis yang dimilikinya, si laki-laki kerdil dapat mengubah jerami menjadi emas. Hal ini memperlihatkan bahwa masyarakat Barat pada saat itu masih kental dengan keyakinan yang mempercayai adanya kekuatan magis yang menyeliputi kehidupan manusia. Hal ini berbeda dari masyarakat 
Timur yang digambarkan dalam Pak Belalang dimana manusia melakukan usaha untuk mencari solusi dalam menyelesaikan persoalan yang mereka hadapi. Ini terlihat dari usaha yang dilakukan Belalang untuk menolong ayahnya menyelesaikan persoalan yang dihadapinya. Belalang berenang menuju kapal dimana nakhoda yang juga seorang nujum menantang untuk mengadu kepandaian dengan ayahnya Belalang yang berpura-pura menjadi nujum pula. Ia berenang dan bersembunyi sambil mencuri dengar pembicaraan sang nakhoda, yang secara kebetulan sedang berbincang tentang pertanyaan dan jawaban yang akan diberikan kepada Pak Belalang. Jadi dapat dikatakan bahwa dari dua cerita rakyatnya tercermin dua budaya yang berbeda dimana masyarakat Barat pada saat karya ini diciptakan masih diselimuti oleh keyakinan terhadap hal-hal magis sedangkan dunia Timur tidak diwarnai dengan pemikiran seperti itu.

Berikut penjabaran lebih lanjut:

\section{Unsur Deux Ex Machina dalam Pak Belalang}

Pak Belalang adalah seorang duda yang pemalas yang mengandalkan anaknya Belalang untuk mencukupi kebutuhan hidupnya. Pak Belalang bernasib baik karena anaknya Belalang yang cerdik selalu memberikannya jalan keluar pada berbagai situasi dan kondisi. Misalnya saat Belalang memberikan gagasan kepada ayahnya agar berpura-pura menjadi ahli nujum (dukun) karena kebetulan Belalang mendengar pembicaraan dua orang pencuri kerbau.

Di waktu yang lain, Pak Belalang diperintahkan Sultan untuk menghadapi seorang nakhoda dari negeri Antan Kesuma untuk beradu kepandaian. Pak Belalang merasa khawatir karena selama ini ia 
hanya berpura-pura menjadi seorang nujum padahal ia tidak memiliki keahlian itu sama sekali. Di saat yang genting itu, Belalang yang mendengar percakapan nakhoda dengan teman-temannya, memberitahukan ayahnya jawaban dari pertanyaanpertanyaan yang akan dilontarkan oleh nakhoda. Di saat genting, di saat Pak Belalang mempertaruhkan nasibnya teks ini menghadirkan Belalang sebagai deux ex machina yang memberikan solusi dalam menyelesaikan permasalahan yang dihadapi tokoh utama. Pak Belalang mampu menjawab semua pertanyaan dari ahli nujum negeri Antan Kesuma. Namun, keberhasilan Pak Belalng tersebut bukanlah karena kesaktian ilmunya, melainkan karena bantuan Belalang yang telah mencuri dengar pertanyaanpertanyaan yang akan diajukan ahli nujum Antan Kesuma sebelum adu kepandaian dilakukan.

\section{Unsur Deux Ex Machina dalam Rumpelstiltskin}

Seorang pemilik pabrik membanggakan anak gadisnya kepada raja. Ia menyombongkan anak gadisnya dan mengatakan bahwa anaknya dapat memintal jerami menjadi emas. Sang raja yang tamak segera memerintahkan putrinya untuk memintal jerami yang banyak untuk dijadikan emas dan bila ia gagal melakukannya maka raja akan menghukum dengan membunuhnya. Keputusan raja ini membuat pemilik pabrik ketakutan dan dan menyesal dengan bualannya, dan putrinyapun merasa putus asa. Putri pemilik pabrik itu menyangka tamatlah riwayatnya karena ia tidak melihat ada jalan keluar dari masalah itu. Di saat genting itu tiba-tiba ia terselamatkan oleh kedatanagan seorang laki-laki kerdil yang memiliki kemampuan magis yang dapat membantunya memintal 
jerami menjadi emas. Sebagai deux ex machina, kejadian ini menyelamatkan sang putri.

Ternyata masalah yang dihadapinya belum sepenuhnya selesai. Raja memerintahkannya memintal lebih banyak jerami untuk dijadikan emas dan setiap kali laki-laki kerdil itu datang membantunya, ia harus memberikan sesuatu sebagai imbalannya, maka ketika tidak ada lagi yang bisa ia berikan, lakilaki kerdil itu meminta bayi yang akan ia lahirkan (setelah putri pemiliki pabrik itu menikah dengan raja) sebagai imbalannya. Karena terdesak dan merasa tidak ada pilihan lain, putri pemilik pabrik itu menyetujui persyaratan tersebut. Setelah ia menikah dengan raja dan menjadi ratu, ia melahirkan seorang anak lakilaki. Maka si kerdil itu pun datang menagih janjinya. Sang ratu merasa sangat sedih dan memohon kepada laki-laki kerdil itu agar jangan mengambil anaknya. Ia bersedia memberikan apapun sebagai gantinya. Namun laki-laki kerdil itu tidak menerima tawarannya.

Walau bagaimanapun, laki-laki kerdil itu merasa iba melihat kesedihan ratu dan memberinya kesempatan tiga hari. Bila sang ratu dapat menebak namanya dalam tiga hari, maka laki-laki kerdil itu tidak akan mengambil bayinya.

Maka sang ratupun mencari yang dapat ia sebutkan dan memikirkan nama-nama aneh yang mungkin merupakan nama si laki-laki kerdil. Sang ratu juga memerintahkan para pengawal itu menyusuri pelosok negeri untuk mencari nama yang mungkin merupakan nama si laki-laki kerdil itu.

Pada hari pertama, lakilaki kerdil itu datang dan menanyakan kepada ratu siapa namanya. Sang ratupun menyebutkan sejumlah nama, namun tidak satupun yang benar. Demikian juga di hari kedua. Pada hari ketiga, sang ratu mulai putus asa. Di saat yang sangat 
kritis itu datang seorang pengawal yang memberi tahu ratu bahwa tanpa ia sengaja ia melihat seorang laki-laki kerdil sedang menari dan bernyanyi dan dalam nyanyiannya, laki-laki itu mengatakan namanya adalah Rumpelstiltskin.

\section{Pengawal yang datang} dengan berita ini merupakan sosok penyelamat yang tiba-tiba muncul untuk menyelamatkan sang bayi. Kejadian ini dimunculkan secara tiba-tiba untuk menyelesaikan persoalan yang dihadapi tokoh cerita ini sebagai deux ex machina.

\section{Perbandingan Unsur- Unsur Deux Ex Machina dalam Pak Belalang dan Rumpelstiltskin}

Kedua cerita rakyat Pak Belalang dan Rumpelstiltskin menggunakan Deux ex machina sebagai jalan keluar untuk menyelesaikan konflik yang dihadapi tokoh utamanya. Dalam Pak Belalang, deux ex machina dihadirkan lewat tokoh Belalang yang sengaja mencari tahu jawaban dari pertanyaanpertanyaan yang akan dilontarkan kepada ayahnya, yang berpurapura menjadi nujum. Dan secara kebetulan (kebetulan yang disengaja) nakhoda kapal sedang menceritakan kepada temantemannya tentang pertanyaan dan jawaban yang akan ia tanyakan kepada Pak Belalang. Deux ex machina ini memperlihatkan bahwa konflik yang diciptakan merupakan jalan untuk menempatkan tokoh utama pada posisi yang baik dan menguntungkan. Ini memperlihatkan keberpihakan karya ini terhadap tokoh utamanya, sehingga terlepas dari tingkah laku sang tokoh yang kurang baik seperti pemalas dan eksploitatif terhadap anaknya, namun teks ini menempatkan Pak Belalang sebagai tokoh yang beruntung.

Berbeda dari sosok Pak Belalang yang pemalas dan 
eksploitatif, putri pemilik pabrik dalam kisah Rumpelstiltskin tidak memperlihatkan prilaku yang buruk. Ia menjadi korban omongan besar ayahnya. Namun sebagi korban, ia dengan tiba-tiba diselamatkan oleh sosok laki-laki kerdil yang datang secara ajaib entah dari mana.

Hal yang sama terjadi lagi di saat putri pemilik pabrik, yang saat itu sudah menjadi ratu menghadapi masalah yang rumit karena ia harus dapat menebak nama laki-laki kerdil yang telah membantunya selama ini. Kalau tebakannya salah maka laki-laki kerdil itu akan mengambil anak sang ratu. Dan sekali lagi permasalahan ini terpecahkam dengan kedatangan seorang pengawal yang secara kebetulan menemukan seorang laki-laki kerdil sedang bernyanyi dan dalam nyanyiannya ia mengatakan namanya Rumperstiltskin.

Dari uraian di atas terlihat bahwa teks Rumpelstiltskin lebih banyak menggunakan deux ex machina dari pada teks Pak Belalang. Ini memperlihatkan bahwa pada masa teks cerita rakyat ini diciptakan, masyarakat Barat sangat menyakini adanya kekuasaan besar di luar kekuasaan manusia yang membantu manusia menyelesaikan persoalan hidupnya. Berbeda dari keyakinan masyarakat barat yang tercermin dalan teks Rumpelstiltskin, tokoh utama dalam teks Pak Belalang terselamatkan karena usaha anaknya sendiri. Jadi nasib baik tokoh ini tidak berdasarkan pertolongan kekuatan magis seperti halnya dalam teks Rumpelstiltskin, melainkan karena ada usaha yang dilakukan manusia (Belalang).

\section{Simpulan}

Terdapat beberapa unsur deux ex machina dalam dua cerita rakyat: Pak Belalang dan Rumpelstiltskin. Dalam Pak Belalang, kejadian ini hadir di saat Pak Belalang diperintahkan 
Sultan untuk beradu kepandaian dengan ahli nujum (nakhoda) dari negeri Antan Kesuma. Masalah ini terselesaikan dengan bantuan $\mathrm{Si}$ Belalang yang berusaha mencari tahu jawaban dari pertanyaan-pertanyaan yang akan dilontarkan kepada ayahnya. Sedangkan dalam Rumpelstiltskin, terdapat dua kejadian yang merupakan deux ex machina. Yang pertama, ketika laki-laki kerdil tiba-tiba muncul entah dari mana, datang untuk membantu putri pemilik pabrik agar dapat memintal jerami menjadi emas. Suatu hal yang mustahil, namun dengan kekuatan magis yang dimilikinya, hal tersebut dapat terjadi. Yang kedua di saat putri pemilik pabrik, yang saat itu sudah menjadi ratu, diberi waktu tiga hari untuk menebak nama si laki-laki kerdil. Jika ia tidak berhasil maka laki-laki kerdil itu akan mengambil anaknya. Di saat genting ini, seorang pengawal secara kebetulan menemukan laki-laki kerdil itu sedang menari dan menyanyi dan dalam nyanayiannya menyebutkan namanya.

Dari berbagai kejadian tersebut, dapat disimpulkan bahwa unsur deux ex machina yang terdapat dalam Rumpelstiltskin lebih banyak ditemukan bahkan sangat berlebihan (dengan menghadirkan kekuatan magis) dibandingkan dengan yang terdapat dalam teks Pak Belalang. Ini memperlihatkan bahwa masyarakat Timur lebih meyakini usaha manusia dibandingkan dengan masyarakat Barat yang lebih meyakini adanya kekuatan magis yang terlibat dalam kehidupan manusia.

\section{Saran}

Cerita-cerita rakyat yang sangat banyak dan beragam, baik cerita rakyat dari dunia Timur maupun dunia Barat sangat kaya akan berbagai unsur dapat dikaji dan ditelaah dari berbagai aspek. Maka dengan adanya kajian sastra banding seperti ini diharapkan 
dapat menginspirasi munculnya

kajian-kajian serupa sehingga

dapat menambah referensi.

Terutama, terhadap objek sastra

rakyat.

\section{Daftar Pustaka}

Arnold, Matthew. On the Modern Element in Literature. Inaugural lecture, delivered in the University of Oxford, 14 Nov 1857.

Bassnett, Susan. 1993. Comparative Literature. Cambridge: Blackwell

Budiman, Manneke. 2005. Tentang sastra Bandingan dalam " Kalam: Jurnal Kebudayaan.” Jakarta.

Grimm Brothers, Rumpelstiltskin, dalam

http://www.authorama.co $\underline{\mathrm{m} / \text { grimms-fairy-tales- }}$

19 maret 2016 25.html-11.25 .

Deus Ex Machina dalam "Urban Dictionary", diunduh dari http://www.urband ictionary.com/define.php?t erm=Deus+Ex+Machina, 14.13, 19 maret 2016

Mahayana, Maman S. 2009. Sastra Bandingan: Pintu Masuk Kajian Budaya. Jakarta.
Newton.P, Ed, dkk. 1990. Sastra Perbandingan: Kaedah dan Perspektif, terj. Sahlan, Mohd Saman. Kuala Lumpur: Dewan Bahasa dan Pustaka, Kementrian pendidikan Malaysia.

Pak Belalang diunduh dari http://cintailahceritarakyat. blogspot.co.id/2011/03/nuj um-pak-

$\frac{\text { belalang.html }}{14.20 .10 \text { maret } 2016}$

Saman, Mohd Sahlan. 1983.

Sastra Bandingan:

Konsep. Teori dan

Amalan. Kuala Lumpur.

Suwardi, Endaswara. 2002. Metodologi Penelitian Folklor: Konsep, Teori dan Aplikasi. Yogyakarya: Med Press.

Weisstein, Ulrich. 1973. Comparative Literature and Literary Theory. Indiana Univ Press. 